\title{
A Liquid Metal Conical Helical Antenna for Circular Polarization-Reconfigurable Antenna
}

\author{
Yun Zhou, ${ }^{1,2}$ Shaojun Fang, ${ }^{1}$ Hongmei Liu, ${ }^{1}$ and Shiqiang Fu ${ }^{1}$ \\ ${ }^{1}$ School of Information Science and Technology, Dalian Maritime University, Dalian, Liaoning 116026, China \\ ${ }^{2}$ School of Physics and Electronic Technology, Liaoning Normal University, Dalian, Liaoning 116026, China \\ Correspondence should be addressed to Shaojun Fang; fangshj@dlmu.edu.cn
}

Received 24 October 2015; Revised 18 December 2015; Accepted 29 December 2015

Academic Editor: Mourad Nedil

Copyright (c) 2016 Yun Zhou et al. This is an open access article distributed under the Creative Commons Attribution License, which permits unrestricted use, distribution, and reproduction in any medium, provided the original work is properly cited.

\begin{abstract}
A novel polarization-reconfigurable conical helical antenna based on the liquid metal is presented. The antenna is implemented by using truncated structure, variable pitch angle, a matching stub, and a mechanical autorotation device. The experimental results show that a good agreement between simulations and measurements is obtained. The gain of the antenna achieves higher than $8 \mathrm{dBi}$ in the work band (1525-1660.5 MHz), and the $3 \mathrm{~dB}$ axial ratio (AR) bandwidth reaches $410 \mathrm{MHz}$. The polarization mode of the antenna can be switched between right-hand and left-hand circular polarization.
\end{abstract}

\section{Introduction}

Antennas have played crucial roles in wireless communication systems. With rapid increase of the number of antennas in communication system, it is a great challenge to improve the electromagnetic compatibility of communication systems. Compared to traditional antennas, a reconfigurable antenna can act as several antennas by changing the antenna's physical structure or incorporating switches. Since the concept of reconfigurable antenna was proposed by Schaubert in 1983 [1], it has attracted more and more attentions. Reconfigurable antennas include frequency-reconfigurable antenna, polarization-reconfigurable antenna, and patternreconfigurable antenna. A frequency-reconfigurable antenna using liquid metal as switching mechanism was proposed by Kelley et al. [2]. With the feature of easy reconstruction, liquid metal antennas attracted a growing number of scholars. In 2009, So et al. found that the liquid eutectic gallium indium alloy (EGaIn) has the ability to fabricate reconfigurable antenna because of its self-healing, which provides a new path for the realization of reconfigurable antenna. In the same year, a bendable frequency-reconfigurable monopole antenna was designed by embedding a liquid metal alloy into a polydimethylsiloxane (PDMS) substrate [3]. It is shown that the resonant frequency of the liquid metal antenna could be tuned by stretching the substrate and then altering the effective length of the antenna. In 2009, Cheng et al. proposed a foldable and stretchable liquid metal planar inverted cone antenna [4]. In 2011, a reconfigurable patch antenna was proposed by Mazlouman et al. which was fabricated by embedding liquid metal (eutectic gallium indium tin alloy, Galinstan) in a silicone substrate [5]. Khan et al. presented a frequency-reconfigurable liquid metal antenna, which was in response to the pressure to adjust the electric length [6]. In 2012, Hayes et al. studied a flexible liquid metal alloy (EGaIn) microstrip patch antenna [7]. A tunable frequency liquid metal monopole antenna has been introduced by several research groups [8, 9]. In 2013 Morishita et al. designed a liquid metal monopole array with tunable frequency, gain, and beam steering [10]. A circular beam-steering reconfigurable antenna with liquid metal parasitic has been demonstrated by Rodrigo et al. [11]. However, the research on helical antenna based on liquid metal has not been found yet.

Circularly polarized antennas are widely used for radar, navigation, and mobile systems [12]. An axial-mode helical antenna, firstly presented by Kraus [13], is an attractive candidate for circularly polarized (CP) applications. A conical helical antenna is a kind of deformation of cylindrical helical antenna, which not only has the advantages of high gain and wide band, but also has the characteristic of sidelobe 


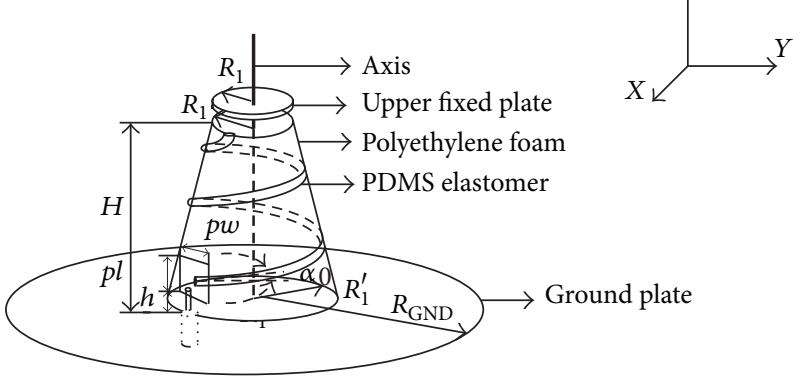

(a)

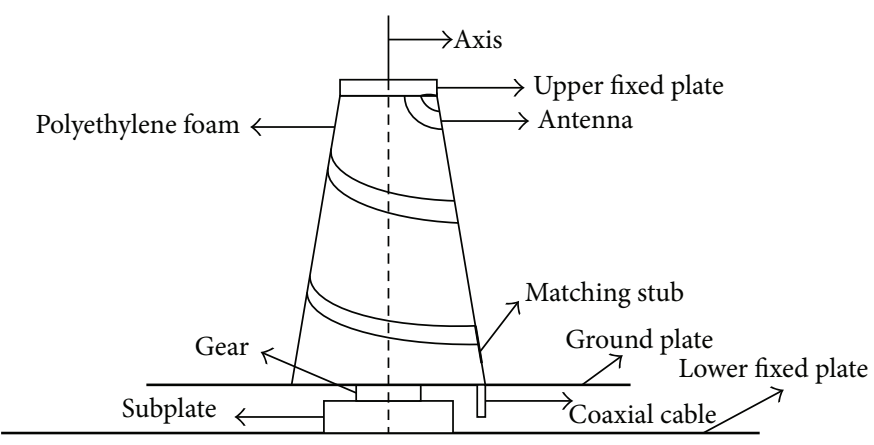

(b)

FIgURE 1: Geometry of the proposed antenna. (a) Panoramic view of the proposed antenna. (b) Side view of the proposed antenna.

suppression. Conical helical reconfigurable antennas based on liquid metal are very important value for applications.

In this letter, a polarization-reconfigurable conical helical antenna using liquid metal enclosed in a polydimethylsiloxane (PDMS) elastomer is introduced. In order to verify the proposed method, an antenna operating in the band (1525$1660.5 \mathrm{MHz}$ ) was designed as an example, and the polarization mode of the antenna can be switched between right-hand and left-hand circular polarization.

\section{Antenna Design}

The proposed polarization-reconfigurable conical helical antenna using liquid metal is enclosed in a tubular PDMS elastomer. PDMS as an elastomer has been used to design the reconfigurable antenna $[3,7]$. The relative dielectric constant of the PDMS is about 2.67. The outer diameter and inner diameter of the PDMS elastomer are, respectively, $6 \mathrm{~mm}$ and $4 \mathrm{~mm}$. Under normal temperature, liquid metal indium gallium alloy (EGaIn) of low melting point is liquid. If exposed to air, EGaIn forms oxide surface and cannot flow. The liquid metal antenna combines the fluidity and ductility of liquid metal with the flexibility of the tubular PDMS, which makes the shape of the antenna easy to adjust. Therefore it has the characteristics of reconfigurability.

Considering portability, the size of the antenna is designed as small as possible. Variable pitch angle and truncated structure are used together, not only to reduce the profile but also to improve the antenna performance [11]. The geometry of the proposed antenna is depicted in Figure 1(a). The parameter equation of conical helical antenna is [14]

$$
\begin{aligned}
& x=\left(R^{\prime}+\frac{R-R^{\prime}}{2 \pi N} t\right) \cos (t), \\
& y=\left(R^{\prime}+\frac{R-R^{\prime}}{2 \pi N} t\right) \sin (t), \\
& z=R^{\prime} \tan \left[\left(\alpha_{0}+\frac{\left(\alpha_{1}-\alpha_{0}\right) t}{2 \pi N}\right) \frac{\pi}{180}\right] t,
\end{aligned}
$$

where the variables $R^{\prime}, R, N, \alpha_{0}$, and $\alpha_{1}$ denote, respectively, the basal radius of the antenna, the top radius of the antenna, the helical turns, the start pitch angle, and the end pitch angle. The variable $t$ represents the radian of the spiral tube, and its scope is $0 \sim 2 \pi N$.

The ratio $D / \lambda$ is an important parameter of the helical antenna. According to antenna theory, when the ratio ranges from 0.25 to 0.42 , the helical antenna will work in axial radiation mode [15]. Beyond this range the helical antenna will no longer exhibit circular polarization characteristics, and lobe pattern may appear distorted. Under the demand of axial radiation pattern, the basal radius of the antenna is chosen as $R^{\prime}=33 \mathrm{~mm}$, the start pitch angle is $\alpha_{0}=14^{\circ}$, and the helical turns are $N=4$. In order to reduce the profile and not to destroy the current distribution on the spiral line [16], the end value of $t$ is selected as $2 \pi \times 2$. The truncated structure is fabricated by cutting off two circles of the antenna, and the remaining part is taken as the body of the conical helical antenna.

The proposed antenna was composed of the ground plate, the matching stub, the supported foam, and the liquid metal EGaIn enclosed in a tubular PDMS elastomer. The tubular PDMS elastomer is wound on conical polyethylene foam (dielectric constant of 1.05) which mounted on a copper ground plate. The feed network is designed by using a matching stub to achieve the excitation. A short vertical feed line penetrates the ground plate through a hole and is connected to the matching stub, as shown in Figure 1(a).

In order to design a polarization-reconfigurable helical antenna, both left and right spiral cylindrical grooves on the conical polyethylene foam were dug. And the radii of the grooves are both $6 \mathrm{~mm}$, which could fit the tubular PDMS appropriately. One end of the tubular PDMS elastomer is fastened on the upper plate which fixes together with the axis and the subplate; the other end is fixed on the matching stub which closes to the ground plate and links the feed line for matching, as shown in Figure 1, while the gear, the ground plate, and the polyethylene foam are fixed together. Motor drives the gear through a belt, and the gear would drive the ground plate and polyethylene foam rotating with the PDMS elastomer. In the process of spinning, the matching stub connected with the antenna could rotate clockwise or 


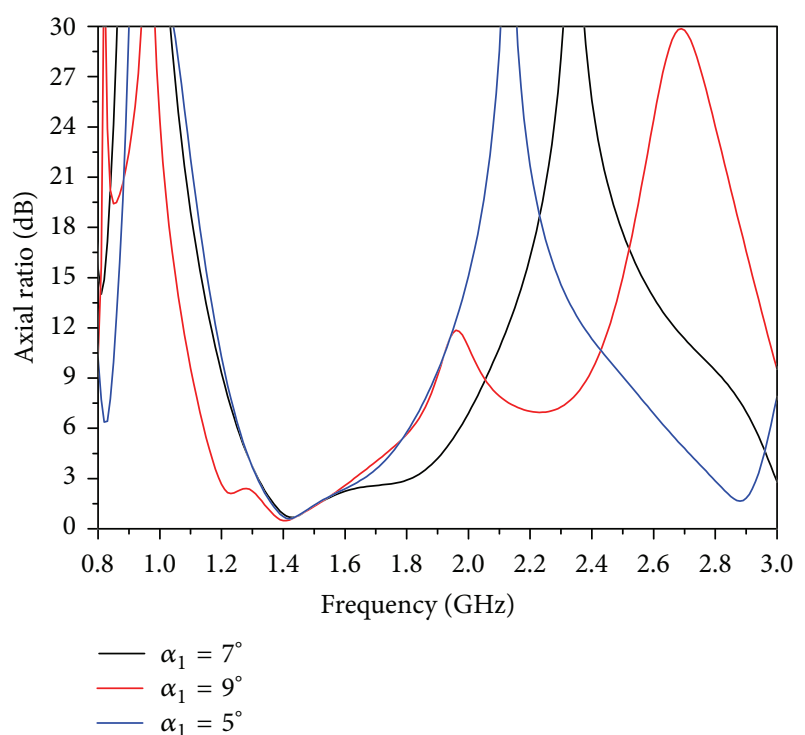

FIGURE 2: Effects of the end pitch angle $\alpha_{1}$ on the axial ratio of the proposed helical antenna $\left(\alpha_{0}=14^{\circ}, R=3 \mathrm{~mm}\right.$, and $\left.R^{\prime}=33 \mathrm{~mm}\right)$.

TABLE 1: Detailed dimensions of the proposed antenna.

\begin{tabular}{lccccc}
\hline Parameters & $R_{1}$ & $R_{1}^{\prime}$ & $R_{\mathrm{GND}}$ & $h$ & $p l$ \\
\hline Value & $14.7 \mathrm{~mm}$ & $30 \mathrm{~mm}$ & $150 \mathrm{~mm}$ & $9 \mathrm{~mm}$ & $24.2 \mathrm{~mm}$ \\
\hline Parameters & $R$ & $R^{\prime}$ & $\alpha_{1}$ & $\alpha_{0}$ & $p w$ \\
\hline Value & $3 \mathrm{~mm}$ & $33 \mathrm{~mm}$ & $7^{\circ}$ & $14^{\circ}$ & $28 \mathrm{~mm}$ \\
\hline
\end{tabular}

anticlockwise. The axis and the subplate which is fastened to one end of the tubular PDMS elastomer are fixed. By starting the motor, the rotation direction of circular polarization of the helical antenna can be changed.

According to the simulation, and based on the value of $R^{\prime}$ and the start pitch angle $\alpha_{0}$, it is found that the end pitch angle $\alpha_{1}$ plays an important role in the current distribution, so it can affect the AR of the proposed antenna. As shown in Figure 2, the $3 \mathrm{~dB}$ AR bandwidth is $24.8 \%$ at $\alpha_{1}=5^{\circ}$; it can be enhanced by increasing the value of $\alpha_{1}$. When $\alpha_{1}=7^{\circ}$ and $\alpha_{1}=9^{\circ}$, the AR bandwidths are both around $33.5 \%$. Considering designing a low profile helical antenna, we choose $\alpha_{1}=7^{\circ}$ in the proposed antenna, which makes the height of the antenna $76 \mathrm{~mm}$.

The significance of the top radius $R$ on the antenna's $3 \mathrm{~dB}$ AR performance is shown in Figure 3 . It is seen that the $3 \mathrm{~dB}$ AR bandwidth is $33.5 \%$ at $R=3$. When $R=5$ and $R=7$, the AR bandwidths are, respectively, $31.6 \%$ and $25.2 \%$. By decreasing the value of $R$, the $3 \mathrm{~dB}$ AR bandwidth can be enhanced.

According to the value given above, the simulation based on HFSS is done. It is found that the imaginary part of the antenna impedance can be controlled by changing the stub width $p w$, as shown in Figure 4(a). And the real part can be regulated by mainly changing the stub length $p l$, as shown in Figure 4(b). Table 1 shows the detailed dimensions of the proposed antenna.

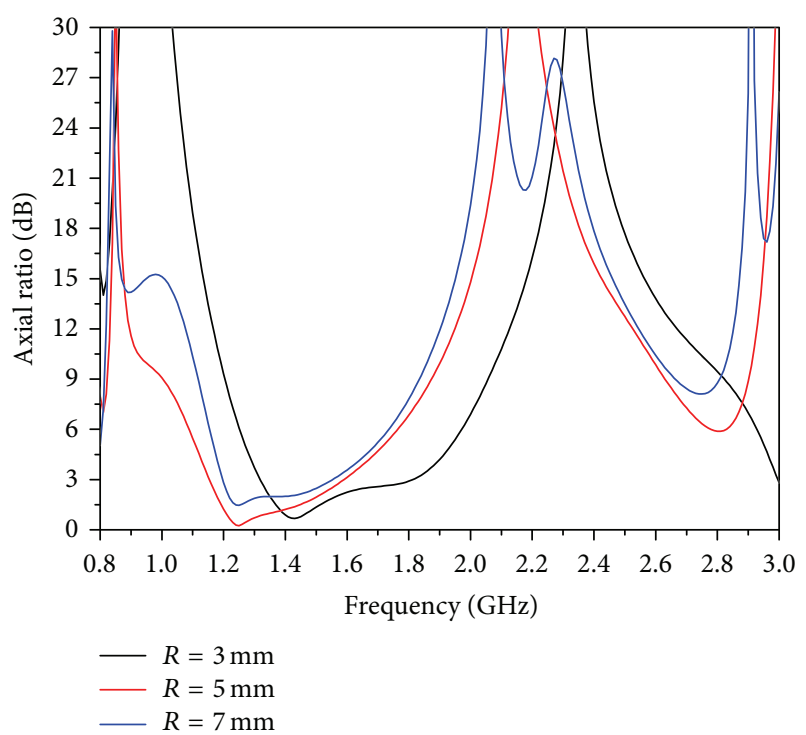

FIgURE 3: Effects of the top radius $R$ on the axial ratio of the proposed helical antenna $\left(\alpha_{0}=14^{\circ}, \alpha_{1}=7^{\circ}\right.$, and $\left.R^{\prime}=33 \mathrm{~mm}\right)$.

\section{Experimental Results}

To demonstrate the validity of the presented design strategy, a prototype of the antenna has been fabricated and measured, as shown in Figure 5.

The measurement was carried out with Agilent N5230A vector network analyzer. From Figures 6(a) and 6(b), it can be seen that the simulated impedance bandwidth for $S_{11}<$ $-15 \mathrm{~dB}$ is from $1.43 \mathrm{GHz}$ to $1.85 \mathrm{GHz}$ and the measured impedance bandwidth for $S_{11}<-15 \mathrm{~dB}$ is from $1.41 \mathrm{GHz}$ to $1.805 \mathrm{GHz}$ for the LHCP, while for the RHCP the simulated impedance bandwidth is from $1.43 \mathrm{GHz}$ to $1.85 \mathrm{GHz}$ and the measured impedance bandwidth is from $1.41 \mathrm{GHz}$ to $1.81 \mathrm{GHz}$, which show reasonable agreements between the simulated and measured results. There exists a little frequency offset between simulation and measurement due to the assembly error.

Figures 7(a) and 7(b) depict the simulated and measured axial ratio and the power gain of the proposed antenna against frequency for the LHCP and RHCP separately. The simulated $3 \mathrm{~dB}$ axial ratio bandwidth is found to be nearly $33.5 \%$ and $30.6 \%$ for the LHCP and RHCP, respectively. Within the whole working band, the measured results demonstrate that the peak gains are higher than $8 \mathrm{~dB}$, and the $\mathrm{AR}$ bandwidth is nearly $410 \mathrm{MHz}$. The measured results are in good agreement with the simulated ones, while the little discrepancy between them can be mainly attributed to fabrication and measurement errors.

The radiation patterns of both RHCP and LHCP at the center frequency $1593 \mathrm{MHz}$ are shown in Figures $8(\mathrm{a}), 8(\mathrm{~b})$, $8(\mathrm{c})$, and $8(\mathrm{~d})$. As can be seen, the measured $3 \mathrm{~dB}$ beam widths for LHCP are about $44^{\circ}$ at $x o z$ plane and $56.4^{\circ}$ at yoz plane, while for RHCP $44^{\circ}$ at $x o z$ plane and $56.2^{\circ}$ at yoz plane. There also exists a little offset between simulation and measurement due to the processing deviation in the antenna fabrication. 


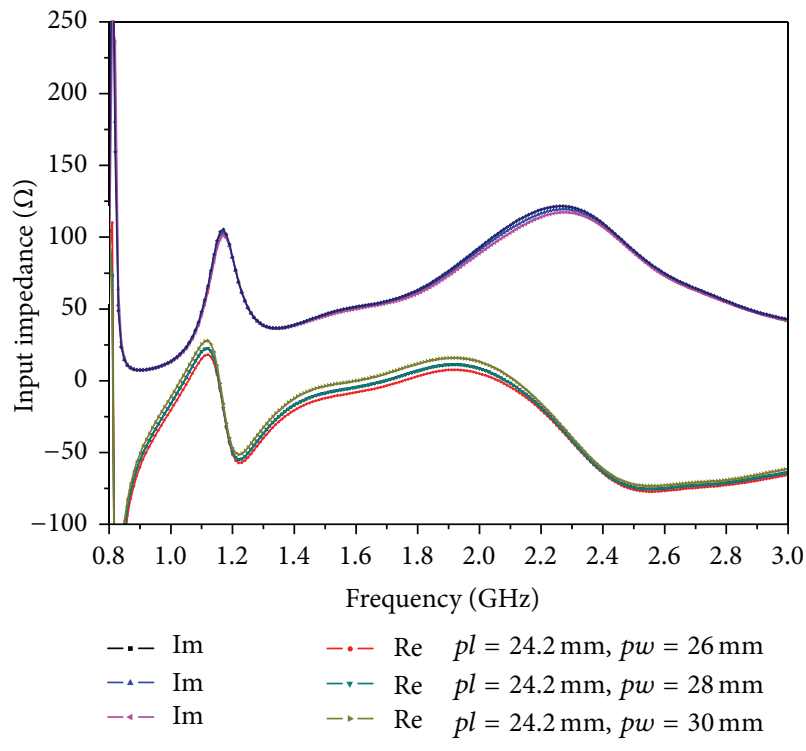

(a)

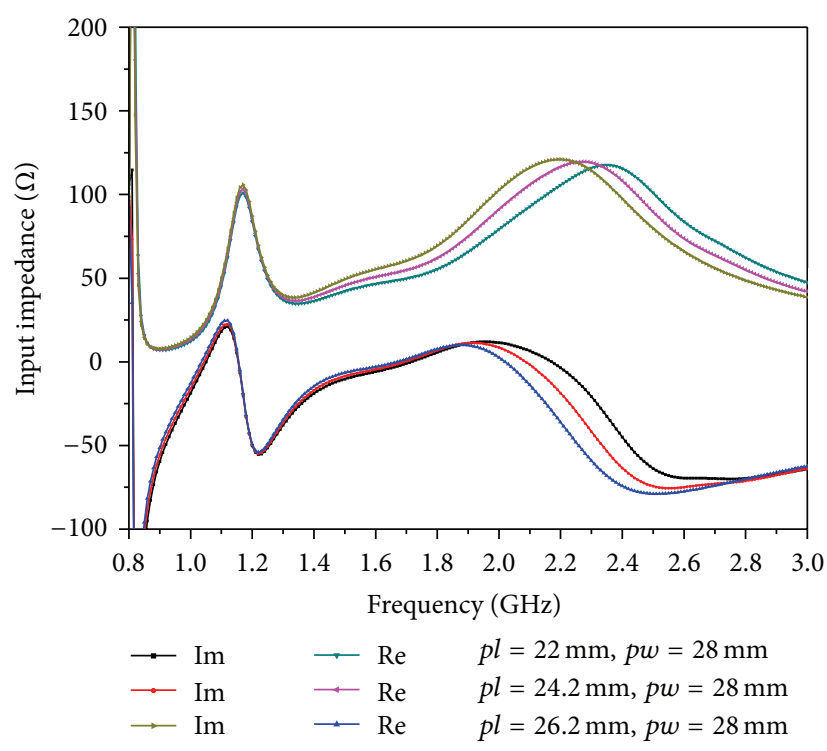

(b)

FIgURE 4: Input impedance as a function of the matching stub length and width. (a) Changing $p w$. (b) Changing pl.

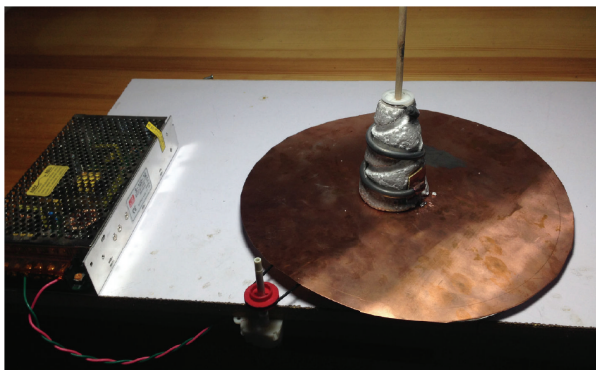

FiguRE 5: Photograph of the proposed antenna.

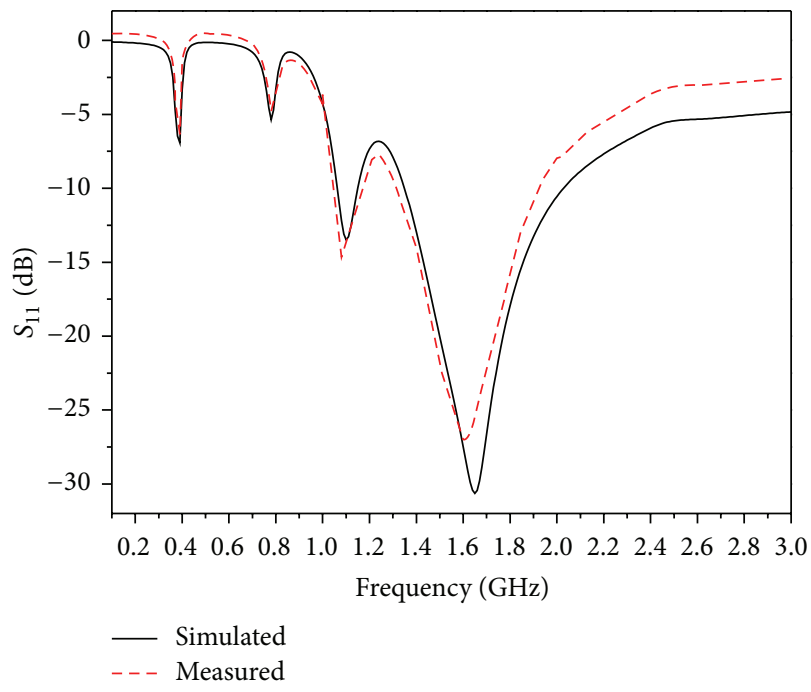

(a)

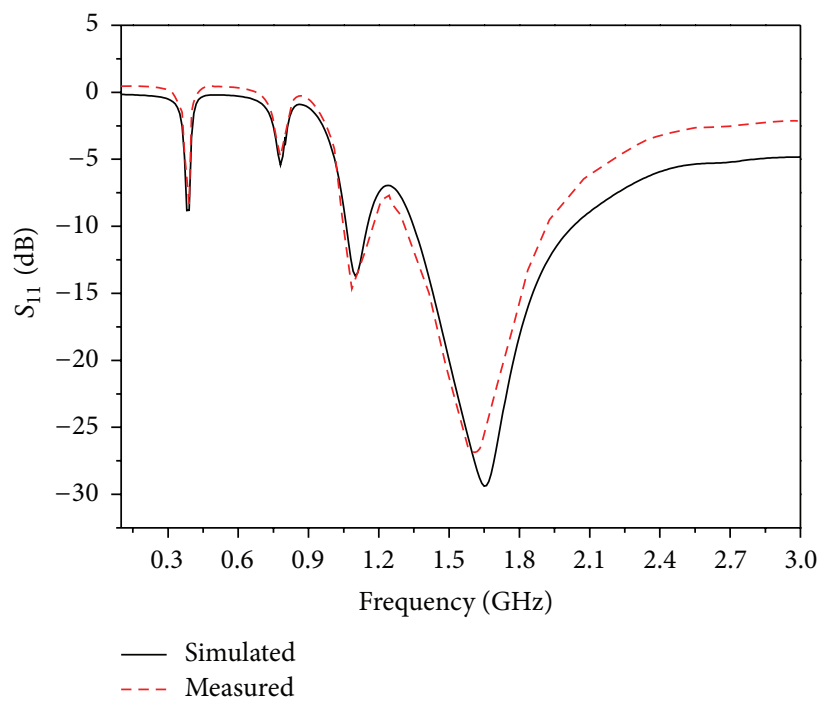

(b)

FIgURE 6: The simulated and measured reflection coefficients. (a) LHCP. (b) RHCP. 


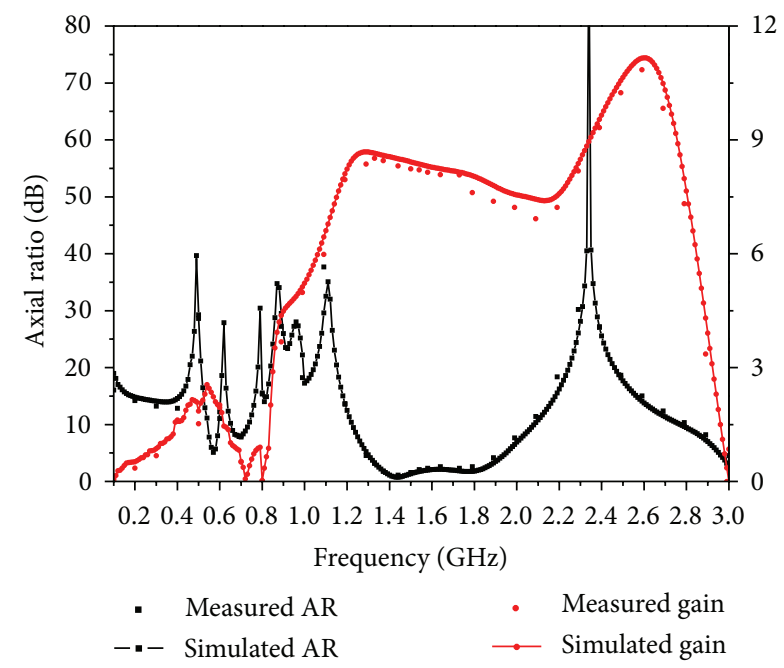

(a)

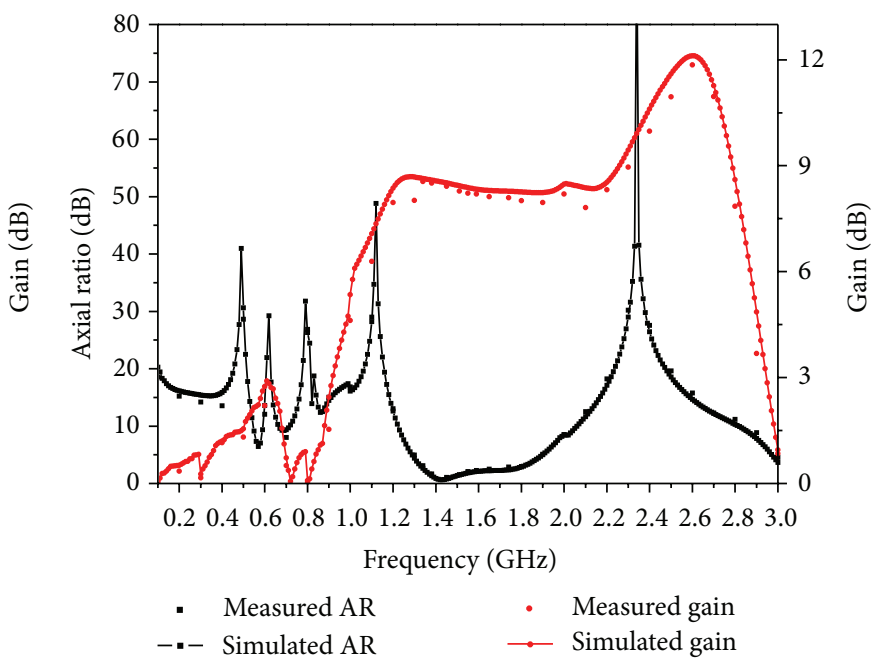

(b)

Figure 7: The simulated and measured axial ratio and gain. (a) LHCP. (b) RHCP.

TABle 2: Performance comparison of the state-of-the-art helical antenna.

\begin{tabular}{|c|c|c|c|c|c|}
\hline Ref. & Structure & $\begin{array}{c}\text { Impedance } \\
\text { bandwidth } \\
\left|S_{11}\right|<-10 \mathrm{~dB} \\
\end{array}$ & $\begin{array}{l}\text { AR bandwidth } \\
(\mathrm{AR}<3 \mathrm{~dB})\end{array}$ & $\begin{array}{l}\text { Height }\left(\lambda_{0} \text { is the }\right. \\
\text { wavelength at the } \\
\text { center frequency) }\end{array}$ & Gain at center frequency $(\mathrm{dB})$ \\
\hline$[18]$ & Nonplanar & $\begin{array}{l}6.9 \% \\
3.4 \% \\
21.7 \% \\
\end{array}$ & $\begin{array}{c}4.2 \% \\
1.3 \% \\
15 \% \\
\end{array}$ & $\begin{array}{c}0.33 \lambda_{0} \\
0.297 \lambda_{0} \\
0.29 \lambda_{0} \\
\end{array}$ & $4.5 \mathrm{dBi}$ \\
\hline [19] & Nonplanar & $9.23 \%$ & $3.2 \%$ & $0.23 \lambda_{0}$ & $4.77 \mathrm{dBi}$ \\
\hline$[20]$ & Nonplanar & $18.2 \%$ & - & $2.96 \lambda_{0}$ & $13 \mathrm{dBi}$ \\
\hline$[21]$ & Nonplanar & $12.8 \%$ & - & $1.11 \lambda_{0}$ & $6.5 \mathrm{dBi}$ \\
\hline$[17]$ & Planar & $54 \%$ & $34 \%$ & $0.11 \lambda_{0}$ & $8 \mathrm{dBi}$ \\
\hline Our work & Nonplanar & $\begin{array}{c}35.6 \%(\text { RHCP }) \\
36 \%(\mathrm{LHCP}) \\
\left(\left|S_{11}\right|<-15 \mathrm{~dB}\right)\end{array}$ & $26.5 \%$ & $0.4 \lambda_{0}$ & $8 \mathrm{dBi}$ \\
\hline
\end{tabular}

Figure 9 depicts that the simulated efficiencies of the same structure antennas vary with the frequency. The conductors are separately the aluminum, the copper, and the EGaIn. As can be seen, the efficiency of the EGaIn antenna is above $90 \%$ within the whole working band.

The simulated efficiencies of the antenna, respectively, by HFSS and CST are shown in Figure 10. It is shown that, within the whole working band, the results keep consistent by different simulator.

Table 2 summarizes the performance comparison of the state-of-the-art helical antennas. Compared to the other nonplanar helical antennas, our proposed antenna clearly exhibits the obvious advantages in terms of impedance and AR bandwidths. It is seen that although the antenna in [17] retains wider impedance and AR bandwidths and has an obvious advantage than others, its structure is planar. In addition, our antenna is a novel design that applied liquid metal to design a polarization-reconfigurable helical antenna. So far, the research on helical antenna based on liquid metal has not been found yet.

\section{Conclusion}

A novel polarization-reconfigurable conical helical antenna with liquid metal is achieved. A truncated structure, a variable pitch angle, a matching stub, and a mechanical autorotation device are adopted in the proposed antenna. The circular polarization radiation mode of the antenna can be switched between the left hand and the right hand. In the entire work band (1525-1660.5 MHz), the gain of the antenna achieves higher than $8 \mathrm{dBi}$ and the $3 \mathrm{~dB}$ axial ratio (AR) bandwidth reaches $410 \mathrm{MHz}$ from $1340 \mathrm{MHz}$ to $1750 \mathrm{MHz}$. Experimental results confirm that the proposed liquid metal conical helical 


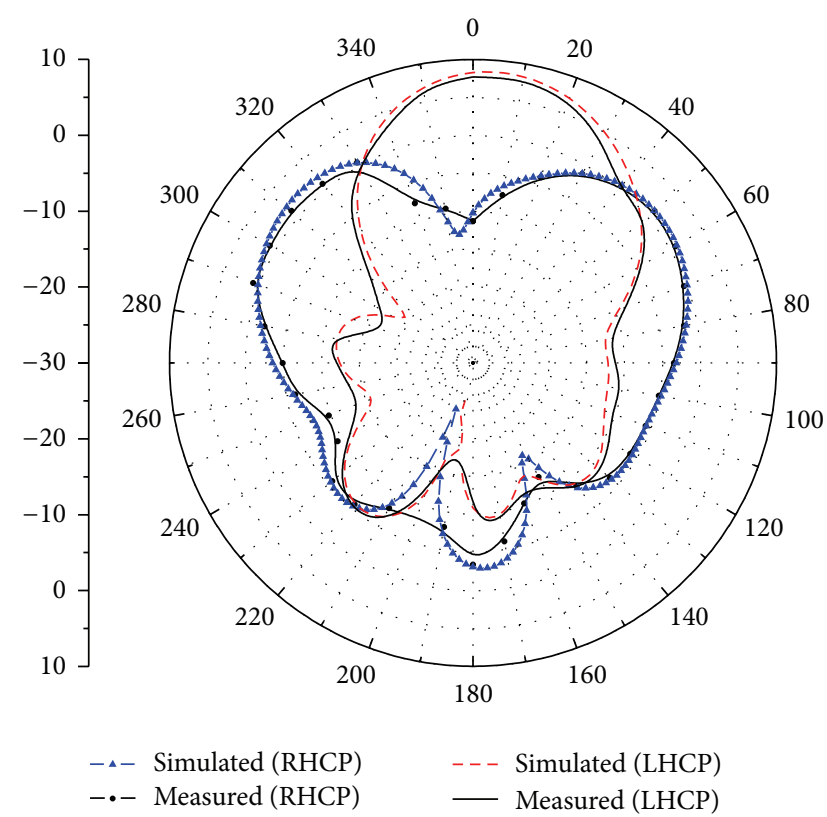

(a)

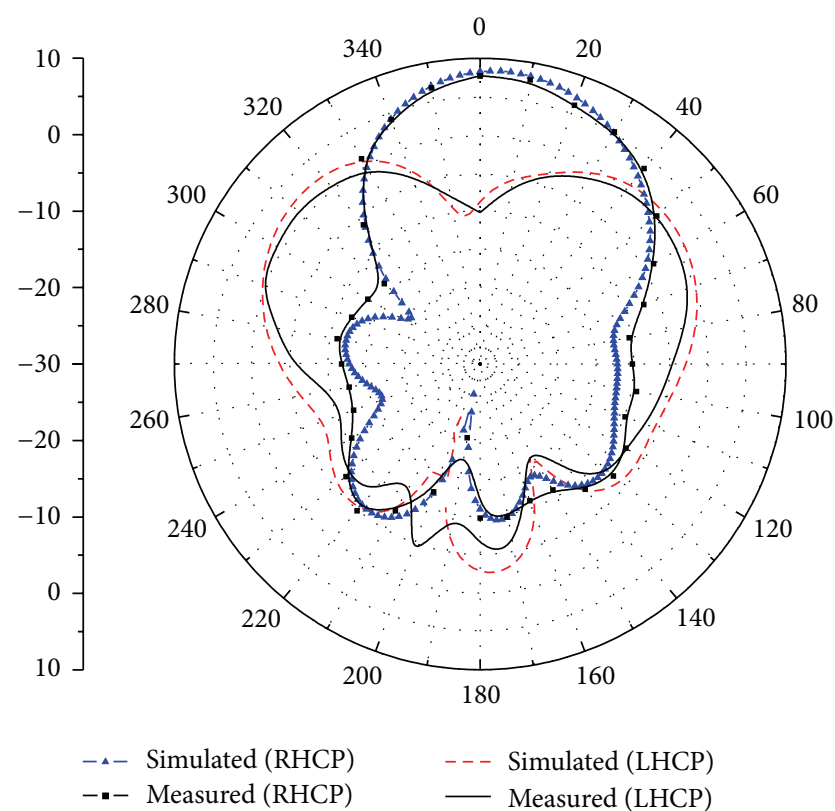

(c)

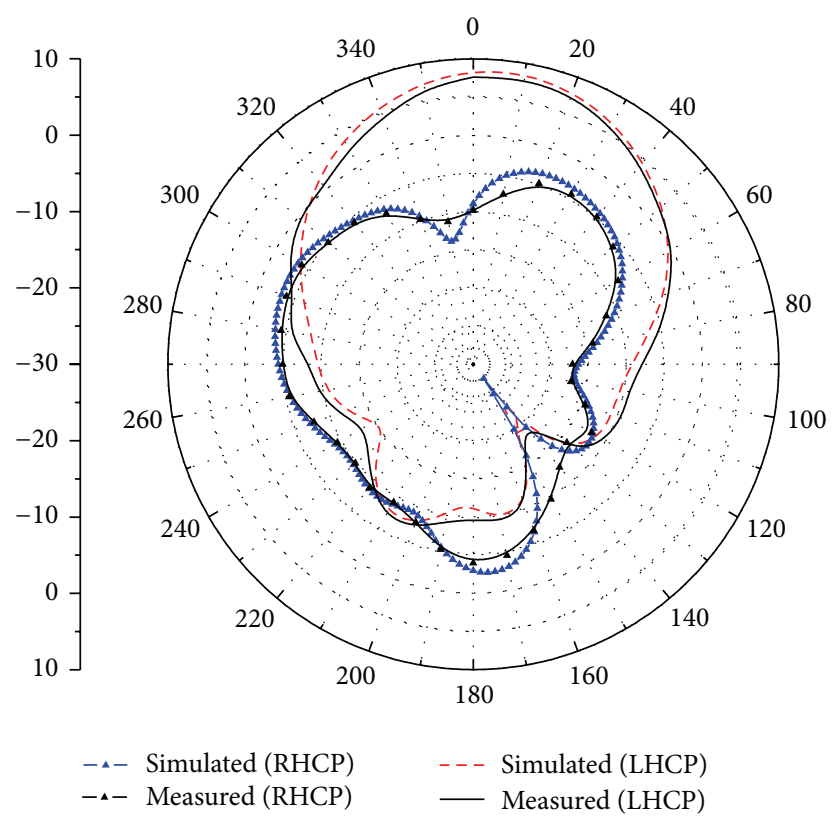

(b)

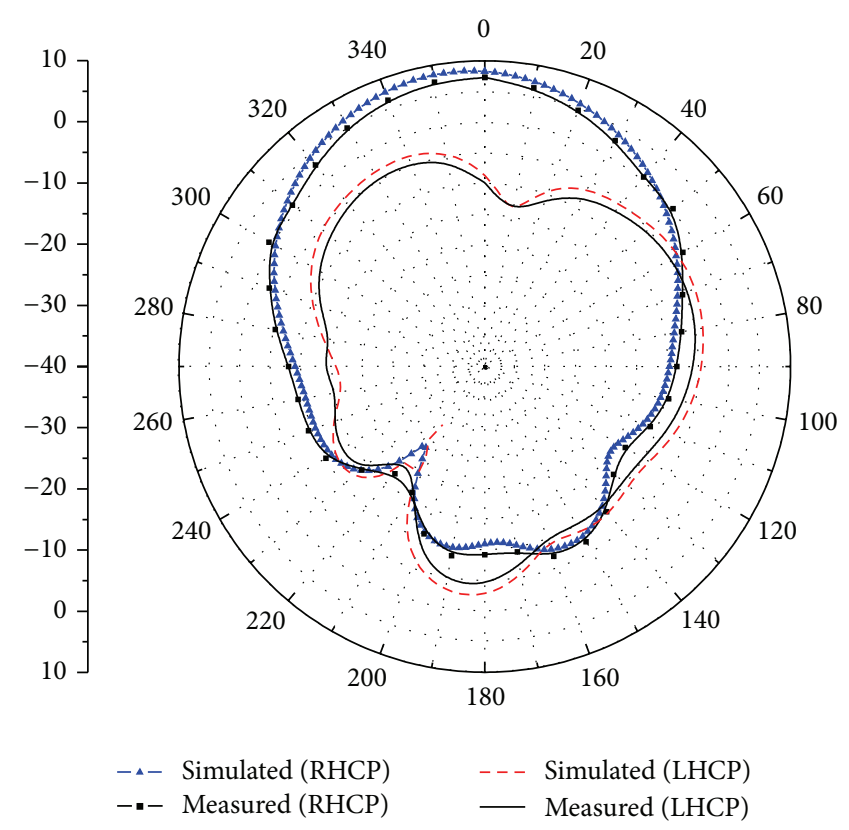

(d)

FIGURE 8: The simulated and measured radiation patterns. (a) LHCP at $x o z$ plane. (b) LHCP at yoz plane. (c) RHCP at $x o z$ plane. (d) RHCP at yoz plane.

antenna can be a good candidate for circular polarizationreconfigurable antenna.

\section{Conflict of Interests}

The authors declare that there is no conflict of interests regarding the publication of this paper.

\section{Acknowledgments}

This work was supported jointly by the National Natural Science Foundation of China (no. 61401056 and no. 61571075), the Scientific Research Project of the Education Office of Liaoning Province (no. L2012171), and the Liaoning Normal University Youth Project (no. LS2014L003). 


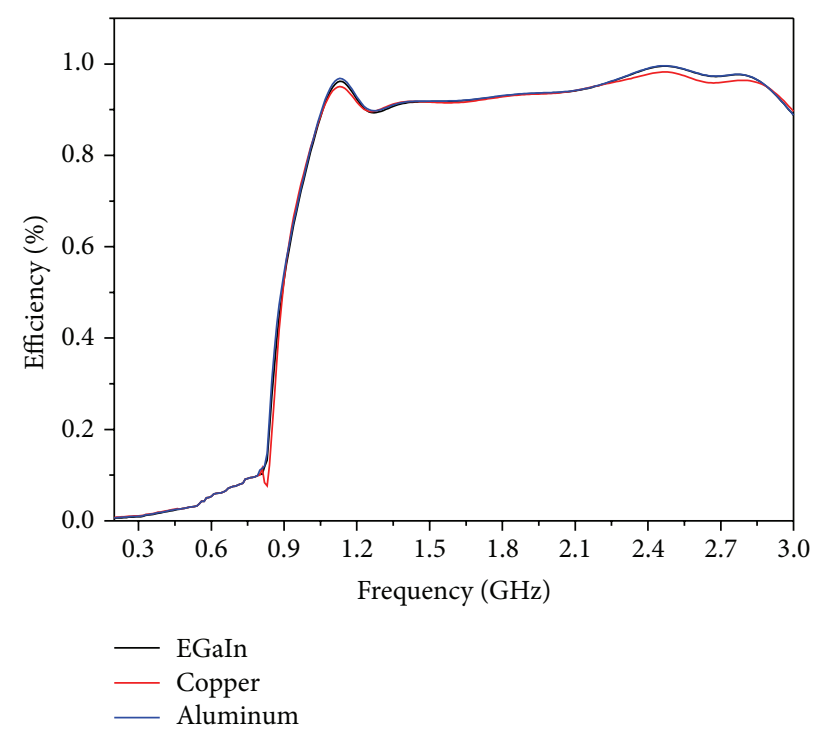

FIGURE 9: Comparison of the efficiency among different conductors.

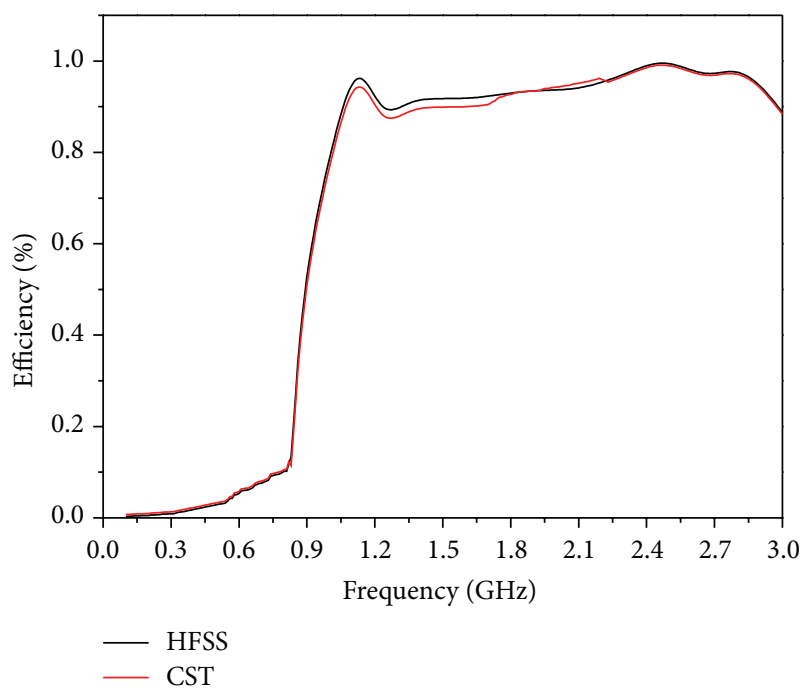

FIGURE 10: Comparison of the efficiency between HFSS and CST.

\section{References}

[1] D. Schaubert, "Frequency-agile, polarization diverse microstrip antennas and frequency scanned arrays," US:US Patent 4367474, 1983.

[2] M. Kelley, C. Koo, H. McQuilken et al., "Frequency reconfigurable patch antenna using liquid metal as switching mechanism," Electronics Letters, vol. 49, no. 22, pp. 1370-1371, 2013.

[3] J.-H. So, J. Thelen, A. Qusba, G. J. Hayes, G. Lazzi, and M. D. Dickey, "Reversibly deformable and mechanically tunable fluidic antennas," Advanced Functional Materials, vol. 19, no. 22, pp. 3632-3637, 2009.

[4] S. Cheng, Z. Wu, P. Hallbjörner, K. Hjort, and A. Rydberg, "Foldable and stretchable liquid metal planar inverted cone antenna," IEEE Transactions on Antennas and Propagation, vol. 57, no. 12, pp. 3765-3771, 2009.
[5] S. J. Mazlouman, X. J. Jiang, A. Mahanfar, C. Menon, and R. G. Vaughan, "A reconfigurable patch antenna using liquid metal embedded in a silicone substrate," IEEE Transactions on Antennas and Propagation, vol. 59, no. 12, pp. 4406-4412, 2011.

[6] M. R. Khan, G. J. Hayes, J.-H. So, G. Lazzi, and M. D. Dickey, "A frequency shifting liquid metal antenna with pressure responsiveness," Applied Physics Letters, vol. 99, no. 1, Article ID 013501, 2011.

[7] G. J. Hayes, J.-H. So, A. Qusba, M. D. Dickey, and G. Lazzi, "Flexible liquid metal alloy (EGaIn) microstrip patch antenna," IEEE Transactions on Antennas and Propagation, vol. 60, no. 5, pp. 2151-2156, 2012.

[8] A. Dey, R. Guldiken, and G. Mumcu, "Wideband frequency tunable liquid metal monopole antenna," in Proceedings of the IEEE Antennas and Propagation Society International Symposium (APSURSI '13), pp. 392-393, IEEE, Orlando, Fla, USA, July 2013.

[9] A. M. Morishita, C. K. Y. Kitamura, A. T. Ohta, and W. A. Shiroma, "Two-octave tunable liquid-metal monopole antenna," Electronics Letters, vol. 50, no. 1, pp. 19-20, 2014.

[10] A. M. Morishita, C. K. Y. Kitamura, A. T. Ohta, and W. A. Shiroma, "A liquid-metal monopole array with tunable frequency, gain, and beam steering," IEEE Antennas and Wireless Propagation Letters, vol. 12, no. 1, pp. 1388-1391, 2013.

[11] D. Rodrigo, L. Jofre, and B. A. Cetiner, "Circular beam-steering reconfigurable antenna with liquid metal parasitics," IEEE Transactions on Antennas and Propagation, vol. 60, no. 4, pp. 1796-1802, 2012

[12] Z.-H. Wu, Y. Lou, J. Bao, and E. K. N. Yung, "A circular patch fed by a switch line balun with printed L-probes for broadband $\mathrm{CP}$ performance," in Proceedings of the IEEE Antennas and Propagation Society International Symposium, pp. 1-4, IEEE, San Diego, Calif, USA, July 2008.

[13] J. D. Kraus, "Helical beam antenna," Electronics, vol. 20, pp. 109111, 1947.

[14] S. Fu, Y. Zhou, S. Fang, and Y. Cao, "Design of low profile and variable pitch angle helical antenna for maritime satellite communications," Chinese Journal of Radio Science, vol. 28, no. 1, pp. 63-67, 2013.

[15] C. A. Balanis, Antenna Theory, Wiley-Interscience, Hoboken, NJ, USA, 3rd edition, 2005.

[16] H. Nakano, H. Takeda, T. Honma, H. Mimaki, and J. Yamauchi, "Extremely low-profile helix radiating a circularly polarized wave," IEEE Transactions on Antennas and Propagation, vol. 39, no. 6, pp. 754-757, 1991.

[17] Z. Chen and Z. Shen, "Planar helical antenna of circular polarization," IEEE Transactions on Antennas and Propagation, vol. 63, no. 10, pp. 4315-4323, 2015.

[18] X. Bai, J. Tang, X. Liang, J. Geng, and R. Jin, "Compact design of triple-band circularly polarized quadrifilar helix antennas," IEEE Antennas and Wireless Propagation Letters, vol. 13, pp. 380-383, 2014.

[19] J. Guo, Y. Yang, Y. Huang, and B. Sun, "Slot multi-arm helix antenna with simple and efficient feeding network," Electronics Letters, vol. 51, no. 16, pp. 1224-1226, 2015.

[20] L. Liu, Y. Li, Z. Zhang, and Z. Feng, "Compact helical antenna with small ground fed by spiral-shaped microstrip line," Electronics Letters, vol. 50, no. 5, pp. 336-338, 2014.

[21] T. L. Zhang, X. Q. Yang, D. L. Fei, and Z. H. Yan, "Single-arm helical antenna with width of arm varying periodically for tilted beam," Electronics Letters, vol. 51, no. 10, pp. 736-738, 2015. 


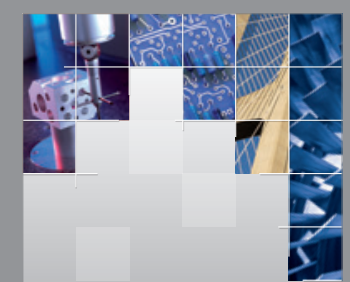

\section{Enfincering}
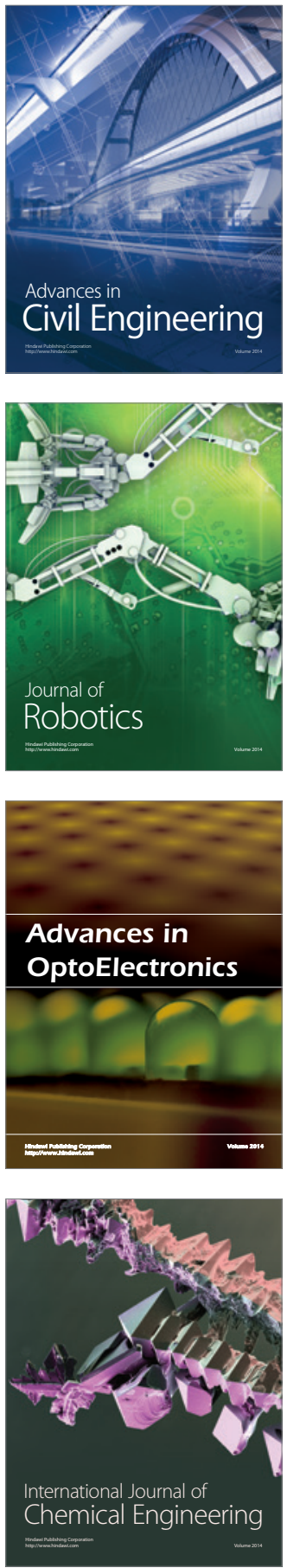

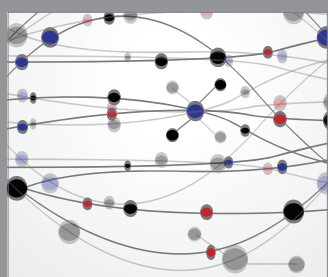

The Scientific World Journal

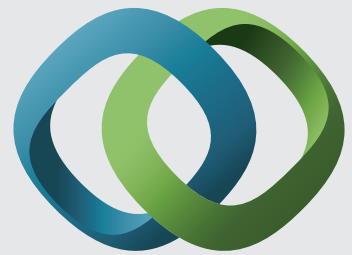

\section{Hindawi}

Submit your manuscripts at

http://www.hindawi.com
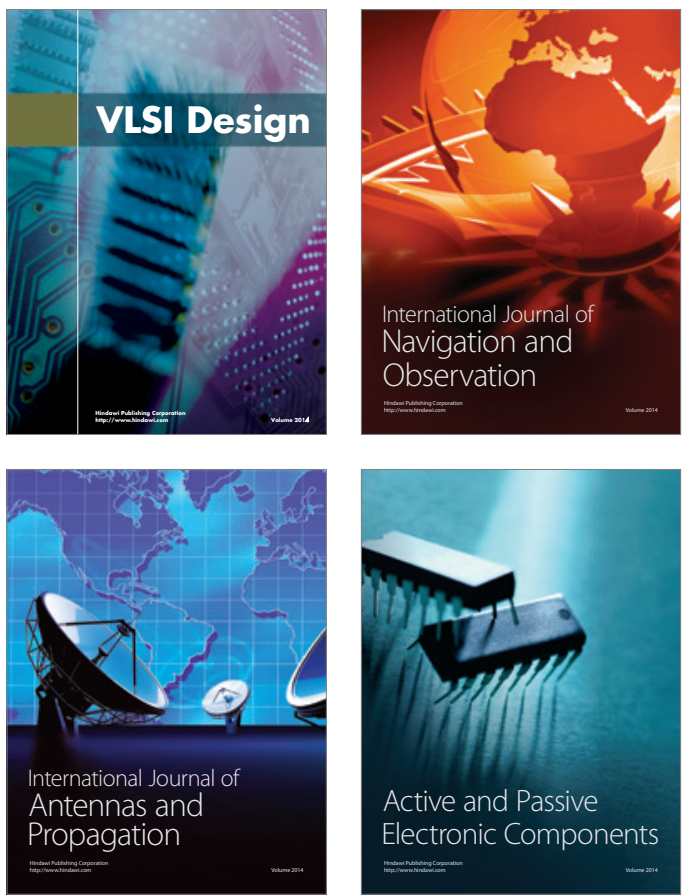
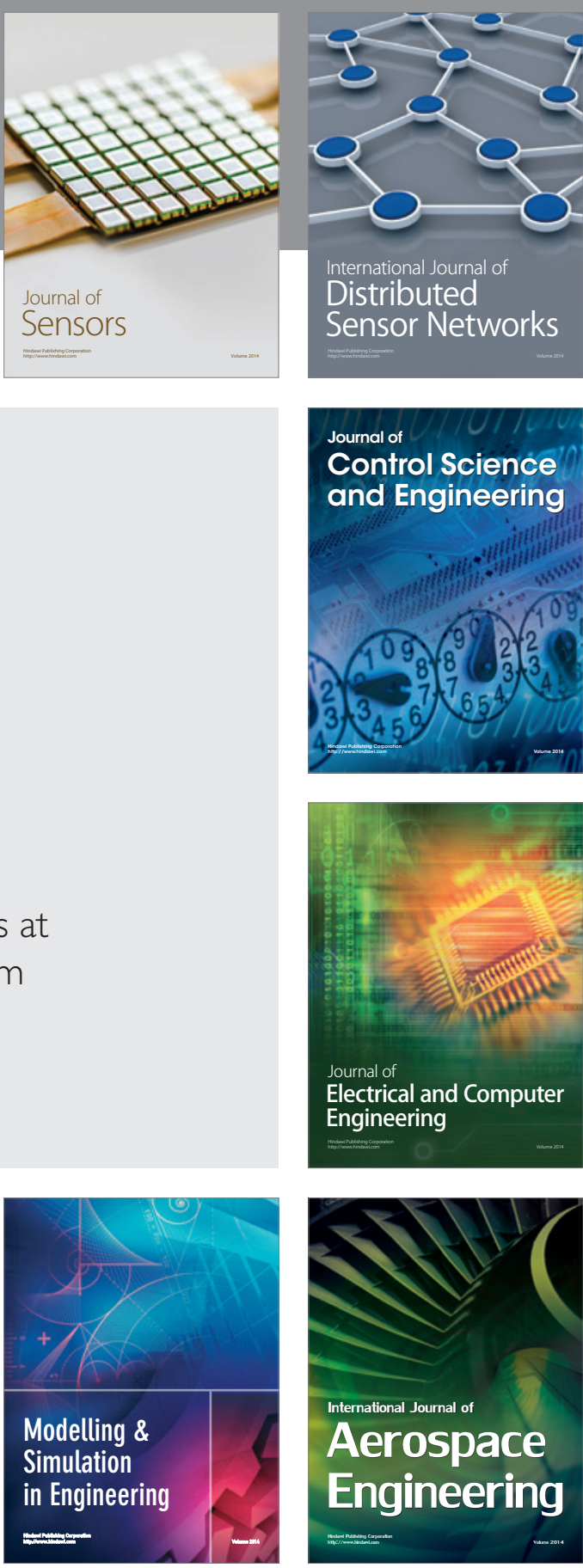

International Journal of

Distributed

Sensor Networks

Journal of

Control Science

and Engineering
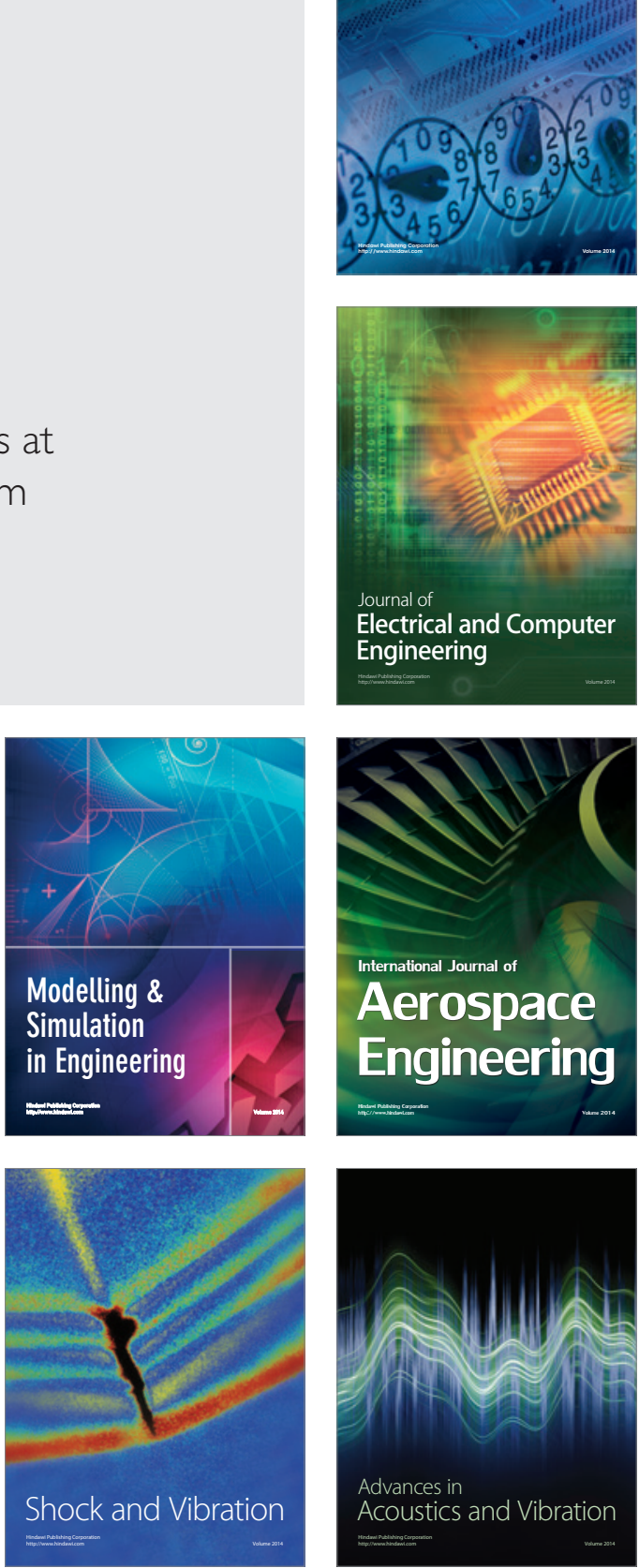